\title{
Clinical and Research Opportunities for Budding Physiologists in India and Abroad
}

\author{
Kaviraja Udupa*, Mrudula Kambhampati, Talakad. N. Sathyaprabha
}

\section{Kaviraja Udupa*, Mrudula Kambhampati, Talakad N. Sathyaprabha}

Department of Neurophysiology, National Institute of Mental Health and Neuro Sciences (NIMHANS), Hosur Road, Bangalore, Karnataka, INDIA.

\section{*Correspondence}

\section{Dr. Kaviraja Udupa, MD}

Additional Professor of

Neurophysiology, National Institute of Mental Health and Neuro Sciences (NIMHANS), Hosur Road, Bangalore-560 029, Karnataka, INDIA.

Phone: +91-80 26995914

Email: kaviudupa@gmail.com

\section{History}

- Submission Date: 22-04-2021;

- Review completed: 02-06-2021;

- Accepted Date: 24-06-2021.

DOI : 10.5530/ijcep.2021.8.2.13

Article Available online

http://www.ijcep.org

\section{Copyright}

(C) 2021 Phcog.Net. This is an openaccess article distributed under the terms of the Creative Commons Attribution 4.0 International license.

\begin{abstract}
There has been increased awareness about choosing the field and career progress in Physiology and its related branches. In spite of the many available resources, there exists a need for proper mentoring and guidance that is required to build up a good career as a physiologist. There is a high demand for physiologists in various fields with the advances in translational research in today's world and young academic Physiologists are stimulated to get them involved in such research activities. These research works not only bring them forward in their careers but also collective efforts from various such research projects help to improve the health conditions and overall well-being of Physiologists. There is increased opportunity both in India and abroad for the young Physiologists to obtain grants, establish laboratory and collaborate with clinicians, epidemiologists and basic scientists to perform quality research. In this review, we will summarize various subdivisions of the major field of physiology and also discuss on the research opportunities, jobs in academic, industry and other scientific fields. Ultimately, the research works and collaboration of physiologists with pharmacologists, physicians, dietitians, fitness coaches, zoologists, clinicians and academicians would hopefully provide lots of satisfaction to the successful investigators, enhanced academic environment and output of the academic institutions ultimately resulting in improvement of overall health of humanity.

Key words: Academic opportunities, career plans, budding physiologists, India and aboard options
\end{abstract}

\section{INTRODUCTION}

In Greek language 'physis' means nature and 'logia' means to study thus, Physiology means the study of nature that is functions of the different cells, organs, and organ systems. ${ }^{[1]}$ Depending on the field of subspecialty, physiology is subdivided into the following: medical physiology, animal physiology, plant physiology, cell physiology, and comparative physiology ${ }^{[2]}$ Physiologist is the term used to represent the resource person who opted to study any subdivision of physiology and understands the function under resting condition as well as during regular or routine activities. Physiologists have many responsibilities which vary from working on cellular molecular aspects to organs and organisms' level. So, the work location is also based on their field or laboratory they work such as cellular laboratories, clinical laboratories, hospitals, Neurophysiologycenters, Moleculargenetics, exercise setups like Gyms, spas, health and fitness centers, animal physiologist, human physiology labs in medical colleges. ${ }^{[3]}$

Cite this article: Udupa K, Kambhampati M, Sathyaprabha TN. Clinical and Research Opportunities for Budding Physiologists in India and Abroad. Int J Clin Exp Physiol. 2021;8(2):49-54. 
positions from Assistant Professor to Professor levels in the field of Animal Physiology. Further, similar to any field of science, one can take up research interests in a specific field (genetics, molecular biology to clinical implications) and work in the direction to achieve growth in their academic career. ${ }^{[5]}$ They also work with the pharmacologists to improve the overall health and well-being of the animals by creating drugs in laboratories. ${ }^{[6]}$

\section{Exercise Physiologist}

An exercise physiologist studies the human body physiology during exercise and physical exertion. The exercise physiologist uses different types of equipment ranging from treadmill, ergo meter, cycling ergo meter, weights, dumbbells and various fitness related equipment. ${ }^{[7]}$ By using these different types of equipment, they study and observe the various rigors of exercise and understand the functions and changes that take place in the human body. According to the age range of the individual they use different types of equipment and the time and effort of the individual varies.

The work of a clinical exercise physiologist involves providing advice and solution on exercise and physical fitness to people with different health ailments and diseases. Metabolic diseases like diabetes, hypertension, coronary artery disease, hypothyroidism, PCOD get benefited with the advice of exercise physiologists. Exercise physiologists help to understand the acute effects and also the chronic adaptations that involved in performing the exercise. They train the patients to follow and practice variety of exercises which can bring up changes in their physical and mental health. They will get placements in the fitness centers and weight reduction clinics where they can suggest the patients with Cardio and Aerobic exercises. Clinical exercise physiologists will be trained in the types of exercises such as aerobic, or endurance, strength, flexibility, balance, stretching etc. Exercise physiologist along with the nutritionists and dieticians and physician work together to understand the type of metabolic disorders and help in providing the appropriate exercise to the patients in helping them in reducing the weight in case of overweight, obesity issues. ${ }^{[8]}$ In case of people opting for body building their role focuses on building the muscle where as in the case of the sports athletes their focus is based on improving the endurance of the sports person. Thus the job opportunities of the exercise physiologists is very broad ranging from gyms, hospitals, sports training centers, clinics attached to various specialized doctors, dietitians, nutritionists, Sports and wellness programs coach, Researcher, Exercise technician, Strength coaches for sports teams and universities, Exercise experts in cardiology clinics and rehab institutions, Fitness instructors in athletics, Electrophysiology technicians, Rehabilitation centers, Hospitals, Doctor's offices, Sports medicine clinics, Physical therapy clinics, College sports programs.

\section{Medical Physiology}

Medicalphysiologyisabranchofphysiologywhichdealswithunderstanding of functions in health and disease. Physiologists in our country after finishing their MD (Physiology) or MSc/PhD (Medical Physiology) join for teaching positions in academic institutions as lecturer or Assistant Professor and start their academic career. The students during their $\mathrm{MD} / \mathrm{MSc}$ are trained in acquiring the skills in various sub branches of physiology such as: cardiac physiology with usage of electrocardiography, cardiac autonomic functions, echocardiography; respiratory physiology with spirometer and pulmonary function tests; Neurophysiology with EEG and sleep studies, nerve conduction and EMG; renal physiology with renal function tests and gastrointestinal physiology with liver function, gastric emptying and gastrointestinal hormonal analysis etc. Medical physiology course training is done at different levels of graduation to Ph.D. Depending on the qualification the student will get placements such as technician jobs with graduation degree; teaching jobs in medical colleges, dental colleges, physiotherapy colleges, nursing colleges, homeopathic colleges with M.Sc he will get as tutor. With earning a Ph.D degree he can get promotion as a professor and he will be even can enter the research and become a basic scientist and enter into the research field. The career for the medical physiologist is wide they can enter into foreign organization and can further pursue post-Doc and begin in setting up a lab with different equipment which can include various tests that can be used in patient assessments for various disorders like cardiac, pulmonary issues.

Medical physiologist can be attached with hospitals and join as technician in cardiac, pulmonary labs, ICU and can be assigned with positions like trained technicians in conducting assessments like electrocardiograph, ECG, Spirometer. ${ }^{[9,10]}$

\section{Clinical Physiology}

Clinical physiology is a diagnostic specialty where patients undergo tests of the functions of various organ systems of our body. Testing methods includes ultrasound, magnetic resonance imaging, positron emission tomography and other techniques like echocardiography and electrocardiography. Clinicalphysiologyand human physiologyaresimilar in the fact that both the subdivisions of physiology involve the study of bodily functions. Clinical physiology examinations involve the assessments of bodily functions. ${ }^{[1]}$ Clinical physiologists and biomedical engineers together as a team are essential in development of new diagnostic techniques and equipment for better treatment approaches. Clinical physiologists also play a role in other fields of expertise like include audiologists, cardiac physiologists, gastrointestinal physiologists, respiratory physiologists, and sleep physiologists. ${ }^{[12]}$

\section{Neurophysiology}

Neurophysiology is the study of the functional properties of neurons, glia, and networks thus investigating physiology and functions of the nervous system. The primary tools of basic neurophysiological research include electrophysiological recordings, such as patch clamp, voltage clamp, extra-cellular single-unit recording and recording of local field potentials. Neurophysiologists have placement in various fields of Neurosciences. Basic graduation level training in techniques like Electroencephalogram can help them in getting a job like technician. Post-graduation in Neurophysiology is useful for getting position like Assistant professor in neurophysiology. One can get a doctoral level degree in Neurophysiology by pursuing Ph.D in neurophysiology. Doctoral degree in neurophysiology is useful in getting a scientist level cadre. Post -doctoral degree in Neurophysiology is useful for conducting research in neurophysiology in different fields like animal experiments like single cell recordings, lesion experiments, invasive brain stimulation for activating the reward circuitry of the animals such as rodents (Rats, Mice), rabbits, guinea pigs and Monkeys. Human experiments such as non-invasive brain stimulation: trans-cranial magnetic brain stimulation, transcranial electrical (direct or alternating) current stimulation, Electroconvulsive therapy (ECT) ${ }^{[13,14]}$ Clinical neurophysiology is a sub branch of neurophysiology which deals with offering experience in the management of adults and children with brain disorders like epilepsy. Duke clinical neurophysiology fellowship program is a one year program which offers training in techniques like Video EEG monitoring with fellowship. Neurophysiologists can even reach positions like CEO of scientific organizations by becoming principle investigators they can apply for some fellowships like ICMR, DST, CSIR, for getting fellowship grants in conducting their research. They can even train the students in getting projects for conducting research in the field of neurophysiology. Where Physiologists Work depending on their interests, physiologists 
may specialize in exercise physiology, diagnosis physiology, neurophysiology, pharmacology, toxicology, pulmonary physiology, or vascularbiology. According totheBureauofLaborStatistics, therearearound 103,100 physiologists and other medical scientists employed throughout the United States. Most physiologists find employment in research institutes, universities, physician offices, pharmaceutical manufacturing companies, medical or surgical hospitals, and other health-related organizations. While the majority of their full-time job is situated within an office or laboratory setting to study data analysis reports, some may need to work with patients to conduct observations for research. In particular, exercise physiologists will use exercise equipment to observe the human body in motion, track specific body systems, and develop treatmentplans. Physiologistssplit theirworkhoursbetween thelaboratory and offices. Some labs include exercise equipment where physiologists can observe the human body in motion and track the activity of particular body systems. The majority of such medical scientists work full-time, typically during regular business hours. A physiologist career typically requires a doctorate and work experience through internships or entrylevel positions. ${ }^{[15]}$

\section{LOOP HOLES IN CONDUCTING QUALITY RESEARCH}

Increased teaching load, difficulty to get the funding for their research ideas and lack of basic research infrastructure in medical colleges will make them good teachers in Physiology but not so good scientists in research. ${ }^{[16]}$

\section{BENEFITS TO PHYSIOLOGISTS WITH COLLABORATION}

However, with emerging fields of translational research, special emphasis is provided to medical students and post-graduates to get trained in hand-on research from the early student/residency period. This coupled with increased infrastructure and collaboration with many clinical departments, resulted in increased research opportunities for the young and budding physiologists. ${ }^{[17]}$

\section{MISCELLANEOUS JOB OPPORTUNITIES}

\section{Medical Writing}

Medical writing is a Flexible job which requires proficiency in sharing their knowledge in multitude modes with common people, doctors, and health workers in a simple but comprehensive way. To become an upstanding medical writer, one needs to focus on improving their skills in the way of communication skills, to efficiently deliver their work in various platforms like workshops, lectures, meetings within the country and also abroad. They will have to deal with projects which needs to follow strict timelines hence one needs to adapt to work efficiently in completing the tasks in stipulated timelines. They will be trained in setting up goals in submitting proposals for obtaining fellowship grants. Qualifications to become a medical writer can be from a graduate degree, post-graduate degree to Ph.D doctoral degree holder.

The medical writer should prepare a resume which is precise and clear in conveying the information about his interests and expertise to the interviewer.

During the preparation of the resume, one should be aware of the field which they are opting to be a medical writer it can be a pharma company, biotechnology company, research organization, healthcare and one needs to acquire knowledge related to the industry he wishes to work in and develop contacts with the people through social platform or attending the workshop and conferences.
Medical writing is an umbrella term which includes a spectrum of subcategories based on the documents they deal with, which can be regulatory medical writing or it can be document writing on clinical trials, which includes study reports, protocols, another subtype is medical communication. Which includes documenting the medical information in the form of written medical case sheets, power points, oral presentation, or even articles from journals from the pharma companies and medical institutes or hospitals.

Qualifications to become a medical writer is a life sciences degree as first degree in graduation, post-graduation, Ph.D, or M.D with biology, physiology or biochemistry. Basic understanding of anatomy and physiology is essential. ${ }^{[18-20]}$

\section{Job Responsibilities}

Physiologists can utilize their knowledge in physiological mechanisms and can assist in the terminology and mechanisms of physiology to assist in writing the manuscript or editing the details or can review the product details with appropriate suggestions in Contract research organization, medical writer for reputed medical journals. ${ }^{[21]}$

\section{Food Processing Industry}

Physiologists assist in assessing the food quality and the composition of the food materials by following the guidelines of food safety officer.

In cosmetics manufacturing companies, physiologists can involve in the research carried out on animals with the new cosmetic product composition and find the quality testing in the laboratory and can also assess if any side effects or reactions to the skin or scalp that can result due to the use of the cosmetic components in the product. Physiologists can also work on the reviewing of the cosmetic products manufactured by a particular company and assessment of its use in the public. ${ }^{[22]}$

\section{Physiologists Can Opt For Jobs in Companies}

Where their responsibility includes Improving the health by understanding disease mechanisms and fundamental biological processes working together with the Engineers through analytics and modeling Drug Discovery, enabling and expediting the identification and optimization of safe and effective drugs by leveraging data science, mechanistic understanding, simulation, and latest AI, Paraxel, Novonordisk, Accenture, Elililly, TCS, Novartis, Cognizant, HCL, inventiv Health, ICON, HCL, PPD, Covance and IBM. In companies like IBM Research Healthcare and Life Sciences team is dedicated in exploring and developing new methodologies and improving many health care challenges like diseases with genetic disorders. From how we can help in the diagnosis of diseases, physiologists play a role in improving the medical support to the patients. To meet the global challenge of COVID-19, the world must come together. Physiologists in collaboration with companies can collaborate by working in these research labs in helping towards improving the facilitation towards designing of vaccines. ${ }^{[23]}$

\section{Physiologists in Instrumentation Development Jobs}

Physiologists can choose their career in medical equipment designing. In History we know many scientists who are physiologists by profession contributed in the development of the medical equipments some examples are Willem Einthoven, who invented electrocardiogram and received the Noble prize, $\mathrm{He}$ invented the first practical electrocardiogram (ECG or EKG) in 1895 and received the Nobel Prize in Physiology or Medicine in 1924 for it («for the discovery of the mechanism of the electrocardiogram". Career prospects of physiology graduates have opportunities in Medical equipment development companies like Bio-medical related companies. (Physiologists in collaboration with Biomedical engineers can be associated in innovatively 
develop an equipment for the better understanding various techniques and mechanisms in research. Establishing strong links between physiologists and other biomedical scientists in establishing national, international, and industrial collaborations is an achievement in the growth of the physiologist career. Equipment like Catheter, Drug delivery devices, Non-invasive Blood pressure monitoring equipment, cardiac assisting equipment, Evoked potential, transcranial magnetic stimulation, electroencephalogram, Visual monitoring equipment. Physiologists will get a career in developing the diverse biomedical equipment which is essential in the diagnostics and analysis of organ injuries and can help in further therapies. ${ }^{[24]}$

\section{Philosophical Works in Yoga and Lifestyle Changes}

Physiologists can get a career in Yoga research in India. Yoga, mind-body medicine, lifestyle modifications, consciousness study center, integrative medicine has been the areas for physiologists to explore the relationship between mind and body. Most of these techniques of yoga are generally advised for healthy person to become 'superhuman' and physiological changes with practice for few weeks to months has always been a topic of research in Physiology. One has to study further, the effectiveness of yoga in preventing various disorders and promoting health across the world. The advanced center for yoga or consciousness under the department of physiology has been in place in various national institutions including JIPMER, AIIMS, NIMHANS. These are actively involved in research activities such as conducting various research projects to explore this gem of Indian philosophy and running various workshops, conferences, CMEs to educate the scope of physiologists into yoga research. Bachelor's degree in Physiology and Anatomy is essential to join in a master's course in yoga. AYUSH India is financially supporting students across the country to conduct research which is also beneficial for educating the aspirants to crack the exam by mentoring them in physiology subject as lecturers. Post-graduation in yoga includes Physiology as a subject in $1^{\text {st }}$ Semester; Physiology PhD holders can apply for a job position as a lecturer to teach these students. ${ }^{[25,26]}$

\section{Other Opportunities for Medical Physiologists}

In addition, there are many funding agencies offering research facilities in established institutions.

1. Ideally it would be advantageous to start from the small project in a well-established laboratory under the guidance of senior Professors

2. It would be ideal for young budding Physiologists to get $\mathrm{PhD}$ and if possible post-doctoral training here in India or abroad before venturing into the role of Principal Investigators in BIG projects.

3. However, this condition is not mandatory as one can pick-up the basics of research even during Masters (M.D/M.Sc) dissertation works.

\section{Occupational Therapist}

Physiologists after their masters can undergo certification programmes like National board for certification in occupational therapy and licensing in Occupational therapy for various states and can opt for jobs in collaboration with the Occupational therapist.

Their role will be in applying knowledge in physiological mechanisms and behavioural sciences to evaluate the degree of disability the patient is facing and helping them in improving on their limitations. They can design and provide interventions to develop skills for community participation. They can conduct sessions to the family members and care givers and supervisors in designing adaptations to the environment to improve access and independence and also designing the devices/tools to offer alternative ways to accomplish activities for a better quality of life of the patients. ${ }^{[27]}$

\section{Job location}

Physiologists with career as an occupational therapist can get placed in schools, rehabilitation centres, mental health facilities, hospitals, client homes, outpatient clinics, and community agencies. Occupational therapist helps in the development of the treatment of strategies to cope up with the illnesses associated with the different illnesses like Alzheimer's disease, Amyotrophic lateral sclerosis, Parkinson's disease and other neurological and psychiatric disorders and children suffering from various disorders like the Autism, Attention deficit hyperactivity disorder, cerebral palsy and disabilities like the loss of the limb (Amputation) during accidents. In countries like U.S physiologists can opt for enrolling in the programmes like the OTD (entry level doctor of occupational therapy or the online post-professional doctor of occupational therapy (PP-OTD). ${ }^{[27]}$

\section{Physiologist as NGOs of Nature Caring, Preserving the Flora and Fauna}

Physiologists can get the job opportunity as an associate scientist and a crop modeller at esteemed organizations like international crop research institute for the semi-Arid tropics (ICRISAT) an agricultural research institute. Their job role would be helping small holder farmers mainly living in the semi-arid tropics area like Asia and the sub- Saharan Africa to overcome poverty, hunger, malnutrition problems and to face the challenges of changing environment as a crop modeller for getting profits in agriculture.

They need to work in a team in discussing ideas and working together to quantify the production limitations of the crops. The job position will be to a senior scientist in crop physiology and principal scientist and regional breeding theme lead. ${ }^{[28]}$

\section{Responsibilities}

These include working as a crop modeller to improve crop productivity. Designing and conducting experiments to improve the crop productivity. Conducting training sessions to improve the knowledge of the students and technical staff. ${ }^{[29]}$

\section{Job requirements}

$\mathrm{Ph} . \mathrm{D}$ degree in quantitative plant physiology knowledge in use of crop simulation and modelling tools. Ability to draft the high-quality research articles.

\section{Educational qualifications}

M.Sc in plant physiology, Ph.D in plant physiology can opt for job position or a post-doctoral fellow position as a crop modeller. Physiologists as the environmental scientist job career is focussed on the study and treat the effects of these natural processes. Physiologists work together with in labs or in medical teams, disaster response personnel. ${ }^{[28]}$

\section{Cardiac Physiologist}

Cardiac physiologists will be placed as:

- Cardiological Technician

- $\quad$ Medical Technical Officer - Cardiology

- Clinical Physiologist - Cardiology

- Cardiac Clinical Scientific Officer

A cardiac physiologist carries out investigations and monitors the activity of the heart. Cardiac physiologists with his knowledge in the physiology of the heart functioning can perform the recording and the analysis of the cardiac parameters.

They record the ECG, Heart rate, Blood pressure monitoring, and help clinicians in diagnosing heart problems which can assist them in prescribing treatment for the cardiac disease. They make use of equipment to record heart rhythm, electrical activity in the heart and other things related to the heartbeat and activity. Their findings are very critical as 
they help doctors to diagnose heart problems or conditions and proffer adequate treatment for such issues. ${ }^{[29,30]}$

\section{Physiologists in Collaboration with the Biotechnologists}

Work together towards improving crop plants genetically while supporting a productive agriculture ecosystem. Their work will be focussed towards the development of the quality of the crop production even in the adverse climatic and environmental conditions. ${ }^{[31]}$

\section{Physiologists as Business Consultants in Health Economics}

In medical schools' students are taught about the anatomy, physiology and different mechanisms and functions of the body along with the clinical and pathological aspects. But what was lacking behind was the idea about the amount of expenditure that was spent on things like infrastructure, policy, economics, informatics these students to complete their studies in the medical school. Physiologists can help in training the faculty and teach the patient safety, quality improvement, health economics. Educating the medical fraternity about the health economics will help in a creating better doctors. Health economics is a branch of economics concerned with issues related to efficiency, effectiveness, value and behavior in the production and consumption of health and health care. Health economics is an umbrella term that works in the collaboration with health care providers, public and private organizations and governments.

\section{Study program}

At abroad schools like Erasmus School of Economics, Rotterdam, Netherlands. The master's program for the health economics includes curriculum which involves an approach towards improving the tools for econometric analysis. In this master's course students' needs to write a thesis, give presentations, and writing the assignments and group discussions. At the end of their curriculum they can volunteer involve in projects like cost-effectiveness of new treatments for life threatening diseases like cancer. Physiologists can pursue these kinds of health economic courses and help in improving the high quality education and research. ${ }^{[32]}$

\section{Job opportunities}

This M.Sc course in health economics will help the research to do quality research in health economics field and become a research project lead. This qualification as a health economist will enable the future career in academics and will provide a scope for employment in fields such as education and government or private sector. ${ }^{[33]}$

\section{Benefits to the Budding Medical Physiologists}

$\mathrm{Ph} . \mathrm{D} /$ post-doctoral fellowship from good recognized institutions would definitely help them for getting a proper foundation in research during this training. Mentorship provided by their supervisors will shape further growth in expanding one's interest in a particular direction. These kinds of mentorship facilities are available in few national institutions and professional organizations. It would be nice to have fruitful networks in regional, national and international levels. This would not only help in getting different ideas but also peer reviewing process involved in grant and manuscript reviewing. Hence junior scientists should prioritize network development strategies and try to build up good network among their peers, senior scientists in the field of their interest. ${ }^{[34,35]}$

\section{DBT-Wellcome India Alliance Early/Intermediate Career Fellowship Eligibility Criteria}

Candidates with a Ph.D degree or an equivalent clinical or public health research experience is required. Candidates with a post graduate degree in Allied health sciences like M.D/MPH degree will be eligible. There is no age limit for applying to this fellowship programme. Candidates need not be resident in India during the application process. They need not have undertaken their Ph.D (or other qualifying degree) in India. India Alliance will provide the financial support for 5 years period. The candidate would not get any other financial support along with Indian alliance funding the candidate however would not be expected to receive any further salary support in addition to India Alliance funding. Fellowships have fixed activation dates with effect from May 2017. For awards recommended in the month of May, the fixed activation date will be 1st January of the following year. For awards recommended in the month of November, the fixed activation date will be $1^{\text {st }}$ September of the following year. It is mandatory for the awarded Fellows to be hosted in the Host Institution for the entire duration of the Fellowship (5 years for Early Career Fellowship). The first year and majority of the final year of the Fellowship must be spent in host institution in India. The host Institute in India is responsible for administering the Fellowship. Hence the fellowship must be activated while in India before the 'Work outside host Institution' option can be availed.

\section{Dual Fellowship Policy}

You may apply even if you already hold another Fellowship. However, please note that if awarded, you will be required to make a choice between your current Fellowship and the India Alliance Fellowship. Eligibility to our Fellowships is calculated from the date of $\mathrm{Ph} . \mathrm{D}$ viva (or date of highest post-graduate medical or Public health degree) to the full application deadline for a particular round of competition.

\section{India Reentry Fellowships for NRIs (Ramalingasamy and Ramanujan) DBT-Wellcome}

Schemes of the Ministry of Science and Technology to provide attractive avenues and opportunities to Indian researchers residing in foreign countries to work in Indian Institutes and Universities:

\section{Ramanujan Fellowship Eligibility Criteria}

Age limit is 40 years. This fellowship is applicable to Indian researchers who are residing abroad and wanted to come back to India to work in Indian Universities.

\section{Ramalinga Swami Re-entry Fellowship}

This fellowship is for Indian nationals working outside the country who would wish to come to India to pursue their research. ${ }^{[36]}$

There is a need to educate students about scope and wide opportunities in the field of physiology both as a area of research and Job opportunities. ${ }^{[37]}$

\section{CONCLUSION}

There is a need for mentor-mentee programs for carrier guidance to help budding physiologists. Physiologists have an opportunity to explore various research possibilities both in India and abroad. Institution or nation can pick up this attitude to work towards positive direction of health of humanity.

\section{ACKNOWLEDGEMENTS}

Authors would like to acknowledge the organizers of $63^{\text {rd }}$ APPI conference, JIPMER Pondicherry where first author of this paper Dr. Kaviraja Udupa was invited to talk on the topic of "Research opportunities for young budding physiologist in India and Abroad" on $10^{\text {th }}$ Oct. 2017 during APPI pre-conference CME on Clinical and Research Opportunities for young and budding Physiologists. This manuscript is based on that talk adding few current and relevant information from various sources. 


\section{CONFLICT OF INTEREST}

The authors declare no conflict of interest.

\section{REFERENCES}

1. Seals DR. Translational physiology: from molecules to public health. J Physiol. 2013;591(14):3457-69. doi: 10.1113/jphysiol.2013.253195, PMID 23732641.

2. Weber GM. Identifying translational science within the triangle of biomedicine. J Transl Med. 2013;11(11):126. doi: 10.1186/1479-5876-11-126, PMID 23705970.

3. Rouse R, Zineh I, Strauss DG. Regulatory science - an underappreciated component of translational research. Trends Pharmacol Sci. 2018;39(3):225-9. doi: 10.1016/j.tips.2017.12.006, PMID 29329784

4. Available from: https://www.simplyhired.com [cited 28/6/2021].

5. Available from: https://learn.org/articles/Animal_Physiologist_Jobs_Frequently_ Asked_Questions.html [cited 28/6/2021].

6. Frye SV, Arkin MR, Arrowsmith CH, Conn PJ, Glicksman MA, Hull-Ryde EA, Slusher BS. Tackling reproducibility in academic preclinical drug discovery. Nat Rev Drug Discov. 2015;14(11):733-4. doi: 10.1038/nrd4737, PMID 26388229.

7. Sasseville VG, Mansfield KG, Brees DJ. Safety biomarkers in preclinical development: translational potential. Vet Pathol. 2014;51(1):281-91. doi: 10.1177/0300985813505117, PMID 24091814.

8. Available from: https://www.careerexplorer.com/careers/exercise-physiologist/ cited 28/6/2021].

9. https://manipal.edu/kmc-manipal/department-faculty/departmentlist/ physiology.html.

10. Hall J. Guyton and Hall textbook of medical physiology. 12th ed. Philadelphia: Saunders/Elsevier; 2011. p. 3.

11. Arheden $\mathrm{H}$. Clinical physiology: a successful academic and clinical discipline is threatened in Sweden. Adv Physiol Educ. 2009;33(4):265-7. doi: 10.1152/ advan.00072.2009, PMID 19948671. S2CID 12888994

12. Clinical Physiology: at the Wayback Machine from. Griffith University; 2013

13. Alexander W. Duke Neuro- and brain event sneak preview, fall Wednesday, September 2; 2020

14. Araus JL, Slafer GA, Reynolds MP, Royo C. Et al. Physiology of yield and adaptation in wheat and barley breeding.

15. THE SCIENCE OF LIFE, Launch your career with a physiology degree. WWW. physoc .org.

16. Clark O. What you can do with a degree in physiology 2020.

17. Faculty of Biology, Careers in physiology. University of cambridge. p. 2020 facbiol@admin.cam.ac.uk.

18. Chung $A$. The perfect Niche for an academic scientist, the medical writing career path, Pharm talk, American Society for pharmacology and experimental therapeutics; 2015.

19. Glassdoor. Medical writer Job salary in India.

20. European medical writers association, A career guide to medical writing 2016.

21. Hukku N. Medical writing as a career - Eligibility and job prospects, Biotecnika info labs 2019.

22. Available from: https://www.research.ibm.com/health care and life sciences. Health care-and-life-sciences.

23. Physiological system and medical devices. Rutgers school of engineering, Department of Biomedical Engineering, The State University of NJ 2020. Available from: https://bme.rutgers.edu/physiological-system-and-medical-devices [cited 28/6/2021].

24. Snellen H. Adrianus, Willem Einthoven. Father of electrocardiography, life and work, ancestors and contemporaries. Dordrecht: Kluwer Academic Publishers. p. 1995 and 1860-927.

25. Available from: https://www.iaspaper.net/m-sc-yoga/ [cited 28/6/2021].

26. Jawaharlal Nehru institute of post graduate medical education and research (JIPMER), Department of physiology General info 2020. Available from: https:// www.jipmer.edu.in/department/physiology/general-info [cited 28/6/2021].

27. Sargent college the occupational therapy graduate programme. Our Occupational Therapy Graduate Program ranks in the nation, as reported by U.S. News and World Report Boston University 2017.

28. Available from: https://www.environmentalscience.org/career/physiologist EnvironmentalScience.org.2020 [cited 28/6/2021]

29. Hall AC. Guyton, john E. Textbook o medical physiology. 11th ed. Philadelphia: W. B. Saunders; 2005. p. 106.

30. Available from: https://ngobox.org/job-detail_Post-Doctoral-Fellow- \%E2\%80\% 93-Crop-Modeller. Physiologist-international-crops-research-institute-for-the-semiarid-tropics-(ICRISAT). Vol. 46884

31. Available from: https://www.routledge.com/Physiology-and-Biotechnology-Integration-for-Plant-Breeding/Nguyen-Blum/p/book/9780367394622 [cited 28/6/2021]

32. Health Economics and Outcome Research, open access; 2020.

33. Erasmus School of Economics, Health Economics MSc Economics and Business. Erasmus university Rotterdam.

34. Swansea University. College of human and health sciences postgrad research courses.

35. Liao J. Anatomy, physiology, and policy: teach medical students about Healthcarecosts,2014 Costshttps://www. Available from: http://wbur.org/cognoscenti/ 2014/01/06/medical-school-healthcare-costs-joshua-liao [cited 28/6/2021]

36. India Alliance DBT wellcome charitable trust in India 2020. Available from: https://www.indiaalliance.org/applicants/remit-and-eligibility [cited 28/6/2021].

37. Tiwari S. Physiologist at crossroads -Options for a stable and fulfilling career. Indian J Physiol Pharmacol. 2020;64(Suppl_1):S38-S40.

Cite this article: Udupa K, Kambhampati M, Sathyaprabha TN. Clinical and Research Opportunities for Budding Physiologists in India and Abroad. Int J Clin Exp Physiol. 2021;8(2):49-54. 